\title{
The Prophylaxis and Treatment with Ondansetron for Postoperative Nausea and Vomiting
}

Wu-yong $\mathbf{Y u}^{1}, \mathbf{Q u}-\mathrm{jin} \mathrm{Li}^{2}$, Chuan-xin-Wu${ }^{2}$ and Jian-ping Gong ${ }^{2 *}$

${ }^{1}$ Department of General Surgery, The Shi Zhu County Hospital, Chongqing, 400010, China

${ }^{2}$ Department of Hepatobiliary Surgery, The Second Affiliated Hospital of Chongqing Medical University, Chongqing, 400010, China

\begin{abstract}
Objective: Postoperative nausea and vomiting (PONV) is the common complication of patients undergoing laparoscopic cholecystectomy (LC). Aim of this study is to determine the efficacy of ondansetron for PONV after LC and exploring the most effective time of using it.

Methods: The clinic data of 120 patients with chronic cholecystitis (selected randomly from all the patients undergone LC at the Second Affiliated Hospital of Chongqing Medical University between 2012 and 2014) were analyzed retrospectively. The data were divided into three groups: the preoperative group $(n=40)$, postoperative group $(n=40)$ and control group $(n=40)$. The preoperative group received $8 \mathrm{mg}$ of ondansetron intravenously 30 minutes prior to the induction of anesthesia while the postoperative group received $8 \mathrm{mg}$ of ondansetron intravenously when anaesthesia recovery, the control group received no antiemetic. The incidence of PONV and the adverse effects during the postoperative periods ( $48 \mathrm{hrs}$ ) were recorded in the data. If the PONV happened, the patients received $8 \mathrm{mg}$ of ondansetron intravenous again.

Results: Significant differences were found between the preoperative group and postoperative group (preoperative: $27.5 \%$ vs. postoperative group: $10 \%$ ) and the preoperative group and control group (preoperative: $27.5 \%$ vs. control group: $50 \%$ ). To the PONV case, using ondansetron intravenous again about $88 \%$ got control. No clinically important adverse effects were noted.

Conclusion: Administration of ondansetron is effective in the prevention and cure of PONV for LC. Late administration (anaesthesia recovery) is significantly more effective.
\end{abstract}

Keywords: Laparoscopic cholecystectomy; Ondansetron;

Postoperative nausea and vomiting

\section{Introduction}

Nausea and vomiting are common complications after surgery operation; some statistics shows that the frequency of nausea and vomiting after operation in hospital surgery patients is $20 \%-37 \%$ [1-4]. PONV is due to the anesthesia and operation for patients with gastrointestinal stimulation. Because of $\mathrm{CO}^{2}$ could take gastrointestinal tracts, so PONV more occurs after LC. PONV is one of the most common complications of the patients after LC.

PONV could cause patients vomit aspiration, could affect sputum expectoration and cause pneumonia, may affect the recovery of intestinal function, could cause wounds pain acutely even because of the increasing of abdominal pressure, the wounds bursting.

Prevention and treatment of PONV help to decrease psychological distress, and advance exhaust and recovery time [2-4].

At present, dexamethasone and metoclopramide are the main drugs for PONV, but the effect not very well. Ondansetron, a selective blocking agent of the serotonin 5-hydroxytryptamine type 3 (5-HT3), the half-life of Ondansetron is $3 \mathrm{hrs}$, the apparent volume of distribution is $140 \mathrm{~L}$ and the plasma protein binding rate is $70-80 \%$. Ondansetron is a highly effective antiemetic that has been used for both the prophylaxis and treatment of PONV [5,6]. However, the most effective time for using of ondansetron for the patients after LC has not been established clearly. Aim of this study is to determine the efficacy of ondansetron for PONV after LC and the most effective time of using it.

\section{Materials and Methods}

\section{Patients and grouping}

The retrospective study selected 120 patients randomly from all the patients undergone LC at the Second Affiliated Hospital of Chongqing Medical University between 2012 and 2014. Exclusion criteria were history of motion sickness or previous PONV, gastrointestinal disorders, use of antiemetic medication within $24 \mathrm{~h}$ before the surgery and smoking habit. All the 120 patients are 60 male patients and 60 female patients, the oldest is 70 years old and the youngest is 20 years old, and the average is 45 years old. All the 120 patients were divided into three groups: the preoperative group $(n=40)$, postoperative group $(n=40)$ and control group $(n=40)$. The information of patients is in Table 1.

\section{Drugs and drug delivery}

All patients received standard anesthesia in the operation room. Patients were monitored during anesthesia by heart beat rate, continuous electrocardiogram, noninvasive blood pressure and peripheral blood oxygen saturation. Anesthesia was induced with fentanyl $0.005 \mathrm{mg} / \mathrm{kg}$, propofol $0.5-2 \mathrm{mg} / \mathrm{kg}$. Anesthesia was maintained with sevoflurane and fentanyl.

The preoperative group received $8 \mathrm{mg}$ of ondansetron intravenously 30 minutes prior to the induction of anesthesia while the postoperative group received $8 \mathrm{mg}$ of ondansetron intravenously when anaesthesia recovery, the control group received no antiemetic. The incidence of PONV and the adverse effects during the postoperative periods ( $48 \mathrm{hrs)}$

*Corresponding author: Gong JP, MD, PhD, Department of Hepatobiliary Surgery, The Second Affiliated Hospital of Chongqing Medical University, Chongqing 400010, China, Tel: 86-13996286589; E-mail: gongjianping11@126.com

Received January 24, 2015; Accepted March 14, 2015; Published March 21 2015

Citation: Yu WY, Li QJ, Wui CX, Gong JP (2015) The Prophylaxis and Treatment with Ondansetron for Postoperative Nausea and Vomiting. Surgery Curr Res 5: 224. doi:10.4172/2161-1076.1000224

Copyright: (c) 2015 Yu WY, et al. This is an open-access article distributed under the terms of the Creative Commons Attribution License, which permits unrestricted use, distribution, and reproduction in any medium, provided the original author and source are credited. 
were recorded in the data.

\section{monitoring index}

The incidence of PONV and the adverse effects during the postoperative periods ( $48 \mathrm{hrs}$ ) were recorded in the data. If the PONV happened, the patients received $8 \mathrm{mg}$ of ondansetron intravenously again. Observe the adverse reactions in $48 \mathrm{hrs}$, such as headache, dizziness, excessive sedation, extrapyramidal reactions and so on.

\section{Data analysis and processing}

The statistical software program Statistical Package for Social Science (version 17.0; SPSS) was used to perform the analysis. Comparisons were assessed by the chi-square test. Differences between groups were declared to be statistically significant at $\mathrm{p}<0.05$.

\section{Result}

The histopathological diagnosis was all chronic cholecystits. The incidence of PONV in the three groups could be found in Table 2 . Compared the preoperative group with the control group, $\chi^{2}=4.27$, $\mathrm{P}<0.05$, the postoperative group with the preoperative group, $\chi^{2}=4.02$, $\mathrm{P}<0.05$, and the postoperative group with the control group, $\chi^{2}=15.24$, $\mathrm{P}<0.05$. The differences between the three groups are all statistical significant.

In the all 120 patients who received LC, there were 35 patients affected by PONV. All the 35 patients were given $8 \mathrm{mg}$ of ondansetron intravenously. The incidence of PONV in patients in each group after therapeutic use could be found in Table 3 .

No clinically important adverse events were found in the data.

\section{Discussion}

Nausea and vomiting due to surgery and anesthesia are among the most common complications. The reported incidence of PONV after LC varies from 50 to $70 \%$ [7-10]. There are many researches for prevention and cure PONV, such as using gabapentin, dexamethasone, perphenazine and so on, they all have efficacy and some side-effects more or less [11-13]. This study we explored the most effective time of using Ondansetron hydrochloride for PONV after LC.

Ondansetron hydrochloride is a highly selective 5 - HT 3 receptor antagonist. It functions so by antagonizing peripheral and central neurons of 5 - hydroxytryptamine receptor, thus blocking intestinal 5 - HT release and blocking the 5 - HT 3 receptor induced vagal afferent nerve excitability caused gag reflex, to the purpose of antiemetic [14]. It is a potent antiemetic with high selectivity effect, without other antiemetic drugs' side effects such as extrapyramidal reactions, sedation. The half-life of Ondansetron is $3 \mathrm{hrs}$, and the apparent volume of distribution is $140 \mathrm{~L}$ and the plasma protein binding rate is $70-80 \%$.

In our department, in more than 600 cases of LC surgery, about $40 \%$ of patients had varying degrees of nausea and vomiting. Therefore, clinicians should pay attention to effective prevention and treatment of PONV, to relieve the suffering of patients after LC.

The reasons of LC postoperative nausea and vomiting are not entirely clear, but most investigations have proposed the following factors: patient characteristics, surgical procedure, anesthetic technique, and postoperative care $[1,2,15,16]$. The surgical procedure, anesthetic technique and postoperative care are the same for all patients who received surgery in our hospital. Therefore, in order to make the study more persuasive, we tried to make the patients we selected have the similar characteristics. For the patient characteristics, such as genders, history of motion sickness, previous PONV, nonsmoking status, and use of postoperative opioids were proposed as predictorsv [17,18]. So, besides the randomness of the selection, we added exclusion criteria in the study. The patients with history of motion sickness, previous PONV, gastrointestinal disorders, previous use of antiemetic medication within $24 \mathrm{hrs}$ before the surgery, or smoking habit were excluded. The male to female ratio is $1: 1$.

We use ondansetron hydrochloride to prevent and treat PONV after LC. About the dosage, there have been many studies, ranging from 1 to $16 \mathrm{mg}$. Some authors considering $4 \mathrm{mg}$ is enough effective dose $[2,19,20]$, whereas others have found $8 \mathrm{mg}$ to be the minimum effective dose [21-23]. In our study, we selected the cases of $8 \mathrm{mg}$ dose in order to make the difference between preoperative group and postoperative group more persuasive.

The results show that with intravenous injection of $8 \mathrm{mg}$ ondansetron 30 minutes before the surgery, the incidence of nausea, vomiting reactions was $27.5 \%$, significantly lower than $50 \%$ of the control group; when inject $8 \mathrm{mg}$ ondansetron intravenously approximately at

\begin{tabular}{|c|c|c|c|c|c|c|}
\hline & $\begin{array}{c}\text { Gender } \\
\text { (male/female) }\end{array}$ & Age $(\overline{\mathbf{X}} \pm \mathbf{S}$ ) & $\begin{array}{c}\text { Weight (kg, } \\
\mathbf{X} \pm \mathbf{S})\end{array}$ & $\begin{array}{c}\text { Height } \mathbf{X} \pm \mathbf{~ S} \text { ) } \\
\text { (cm, }\end{array}$ & Operation time (min, $\overline{\mathbf{X}} \pm \mathbf{S})$ & Anesthesia time (min, $\overline{\mathbf{X}} \mathbf{S} \mathbf{S})$ \\
\hline Preoperative group & $20 / 20$ & $45.2 \pm 13.7$ & $62.5 \pm 10.3$ & $162.1 \pm 8.7$ & $40.1 \pm 16.3$ & $85.4 \pm 22.4$ \\
\hline Postoperative group & $20 / 20$ & $43.7 \pm 14.5$ & $63.4 \pm 11.7$ & $165.2 \pm 9.3$ & $39.9 \pm 15.8$ & $83.2 \pm 21.8$ \\
\hline Control group & $20 / 20$ & $46.1 \pm 14.1$ & $63.1 \pm 12.6$ & $162.8 \pm 7.2$ & $39.6 \pm 16.7$ & $82.7 \pm 20.6$ \\
\hline
\end{tabular}

Table 1: The information of patients.

\begin{tabular}{|c|c|c|c|}
\hline & Num. of cases & Cases of PONV & Incidence(\%) \\
\hline Preoperative group & 40 & 11 & 27.5 \\
\hline Postoperative group & 40 & 4 & 10 \\
\hline Control group & 40 & 20 & 50 \\
\hline
\end{tabular}

Table 2: Incidence of PONV in patients of each group after prophylactic antiemetic.

\begin{tabular}{|l|c|c|c|}
\hline & Num of cases & Cases of PONV & Incidence(\%) \\
\hline Preoperative group & 11 & 1 & 9 \\
\hline Postoperative group & 4 & 0 & 0 \\
\hline Control group & 20 & 3 & 15 \\
\hline
\end{tabular}

Table 3: Incidence of PONV in patients in each group after therapeutic use. 
end of surgery, the incidence was $10 \%$, significantly lower than that of preoperative group and control group. It shows that ondansetron can be effective in preventing PONV and the proper time is injected at the end of the surgery. Meanwhile, of all the 120 patients, 35 patients affected by PONV received ondansetron $8 \mathrm{mg}$ intravenously, and 31 of them got symptom-free, and the remaining 4 patients had varying degrees of ease. It shows that ondansetron can also be effective in treating PONV.

The most effective timing of ondansetron administration has been an issue in several reports. Some reports had no significant difference [24]. Other reports, on the other hand, did not have take all the risk factors in control and the surgery procedure for the study was not LC [6]. Our study indicated that PONV occurred in $27.5 \%$ of the patients who received ondansetron just before the induction of anesthesia of LC, but when given at the end of surgery, the incidence decreased to $10 \%$. The difference was significant and the risk factors were all taken in control. The reasons could be that ondansetron could reach plasma peak concentration within 10 minutes by intravenous administration, and it has many metabolic pathways, and hydrochloride in vivo elimination half-life is $3 \mathrm{hrs}$. In LC, the time of anesthesia is about 84 minutes, so its antiemetic benefit may be lost in long operation time. So after the operation, the drug concentration has been reduced, and could not perform the anticipated antiemetic function effectively. At that moment, another time of intravenous ondansetron use could be increase the drug concentration in vivo in patients, and then we can effectively achieve the antiemetic purposes.

Our study had a potential limitation. It was a retrospective study which is not as persuasive as a prospective study. However, we had to do it like this in order to take all the risk factors in control.

\section{Conclusion}

Administration of ondansetron is effective in the prevention and cure of PONV for LC. Late administration (anaesthesia recovery), compared to preoperative administration (within $30 \mathrm{~min}$ before surgery), is significantly more effective in the prevention of PONV for LC.

\section{References}

1. Sikka R, Kaul TK, Grewal A, Satjita A (2007) Post operative nausea and vomiting. J Anesth Clin Pharmacology 23: 341-356.

2. Fujii $Y$ (2011) Management of postoperative nausea and vomiting in patients undergoing laparoscopic cholecystectomy. Surg Endosc 25: 691-695.

3. Stadler M, Bardiau F, Seidel L, Alberta A, Boogaerts JG (2003) Difference in risk factors for postoperative nausea and vomiting. Anesthesiology 98: 46-52.

4. Tramèr MR (2004) Strategies for postoperative nausea and vomiting. Best Pract Res Clin Anaesthesiol 18: 693-701.

5. Misra MN, Pullani AJ, Mohamed ZU (2005) Prevention of PONV by acustimulation with capsicum plaster is comparable to ondansetron after middle ear surgery. Can J Anesth 52: 485-489.

6. Cruz NI, Portilla P, Vela RE (2008) Timing of ondansetron administration to prevent postoperative nausea and vomiting. PRHSJ 27: 43-47.

7. Henzi I, Walder B, Tramèr MR (2000) Dexamethasone for the prevention of postoperative nausea and vomiting: a quantitative systematic review. Anesth Analg 90: 186-194.

8. Fujii $Y(2005)$ The utility of antiemetics in the prevention and treatment of postoperative nausea and vomiting in patients scheduled for laparoscopic cholecystectomy. Curr Pharm Des 11: 3173-3183.

9. Sánchez-Rodríguez PE, Fuentes-Orozco C, González-Ojeda A (2010) Effect of dexamethasone on postoperative symptoms in patients undergoing elective laparoscopic cholecystectomy: randomized clinical trial. World J Surg 34: 895900

10. M Arslan, R Çiçek, HÜ Kalender, et al. Preventing Postoperative Nausea and Vomiting After Laparoscopic Cholecystectomy: A Prospective, Randomized Double-Blind Study. Curr Ther Res Clin Exp 72: 1-12.

11. Achuthan S, Singh I, Varthya SB, Srinivasn A, Chakrabarti A, et al. (2015) Gabapentin prophylaxis for postoperative nausea and vomiting in abdominal surgeries: a quantitative analysis of evidence from randomized controlled clinical trials. $\mathrm{Br} \mathrm{J}$ Anaesth: 449.

12. Si XY, Wu LP, Li XD, Li B, Zhou YM (2015) Dexamethasone combined with other antiemetics for prophylaxis after laparoscopic cholecystectomy. Asian J Surg 38: 21-27.

13. Schnabel A, Eberhart LH, Muellenbach R, Morin AM, Roewer N, et al. (2010) Efficacy of perphenazine to prevent postoperative systematic review. Eur J Anaesthesiol 27:1044-1051.

14. Blower PR (1999) Comparative pharmacology of 5-HT3 recepter antagonists. Hospital Formulary 29: 4.

15. Fujii $\mathrm{Y}$, Tanaka $\mathrm{H}$, Kawasaki $\mathrm{T}$ (2004) Effects of granisetron in the treatment of nausea and vomiting after laparoscopic cholecystectomy: a dose-ranging study. Clin Ther 26: 1055-1060.

16. Fujii Y, Tanaka H, Kawasaki T (2000) Randomized clinical trail of granisetron, droperidol and metoclopramide for the treatment of nausea and vomiting after laparoscopic cholecystectomy. Br J Surg 87: 285-288.

17. Apfel CC, Grein CA, Haubitz I, Goepfert C, Usadel J (1998) A risk score to predict the probability of postoperative vomiting in adults. Acta Anaesthesiol Scand 42: 495-501.

18. Sinclair DR, Chung F, Mezei G (1999) Can postoperative nausea and vomiting be predicted?. Anesthesiology 91: 109-118.

19. Metaxari M, Papaioannou A, Petrou A, Chatzimichali A, Pharmakalidou E, et al. (2011) Antiemetic prophylaxis in thyroid surgery: a randomized, double-blind comparison of three 5-HT3 agents. J Anesth 25: 356-62.

20. Liberman MA, Howe S, Lane M (2000) Ondansetron versus placebo for prophylaxis of nausea and vomiting in patients undergoing ambulatory laparoscopic cholecystectomy. Am J Surg 179: 60-62.

21. Quaynor H, Raeder JC (2002) Incidence and severity of postoperative nausea and vomiting are similar after metoclopramide $20 \mathrm{mg}$ and ondansetron $8 \mathrm{mg}$ given by the end of laparoscopic cholecystectomies. Acta Anaesthesiol Scand 46: 109-113.

22. Paventi S, Santevecchi A, Ranieri R (2001) Efficacy of a single-dose ondansetron for preventing postoperative nausea and vomiting afte laparoscopic cholecystectomy with sevoflurane and remifentanil infusion anaesthesia. Eur Rev Med Pharmacol Sci 5: 59-63.

23. Ryu J, So YM, Hwang J, Do SH (2010) Ramosetron versus ondansetron for the prevention of postoperative nausea and vomiting after laparoscopic cholecystectomy. Surg Endosc 24: 812-817.

24. Sun R, Klein KW, White PF (1997) The effect of timing of ondansetron administration in out patients undergoing otolaryngologic surgery. Anesth Analg 84: 331-336.T 